\title{
Interactive effect of Meloidogyne incognita and Macrophomina phaseolina on the development of root-rot disease complex in relation to growth and physiological attributes of chickpea
}

\author{
A. Sumbul* and I. Mahmood
}

Summary The interactive relationship between the root-knot nematode Meloidogyne incognita and the root-rot fungus Macrophomina phaseolina in a root-rot disease complex of chickpea (Cicer arietinum var. avrodhi) was studied in a net house. The present study was carried out in such a manner so that the pathogenic potential of $M$. incognita and $M$. phaseolina individually, simultaneously and sequentially could be monitored. The pathogens singly as well as in combination led to significant reduction in growth, yield, nutrient and biochemical parameters. Gaseous exchange parameters like photosynthetic rate, transpiration rate and stomatal conductance were also reduced following infection of plants by the pathogens. However, maximum reduction was noticed in simultaneous inoculation with both pathogens. Sequential inoculation, where M. incognita preceded M. phaseolina by 15 days, was more damaging to the crop in comparison to that where $M$. phaseolina preceded $M$. incognita inoculation by 15 days. Infection by M. phaseolina caused a considerable reduction in the number of galls, egg-masses and nematode multiplication, with the highest reduction observed in plants simultaneously inoculated with the pathogens. Those plants also showed the highest disease severity in terms of percent root-rot. Thus, a manifold action plan to reduce the impact of the root-rot disease complex on chickpea crops has to be formulated.

Additional keywords: Cicer arietinum, gaseous exchange, interaction, nutrients, pathogenic potential

\section{Introduction}

Chickpea (Cicer arietinum L.) is the second most essential pulse crop after beans in the world both area wise (13.5 million ha) and production (13.1 million tons) (FAOSTAT, 2016). India is the largest producer of chickpea in the world contributing about $63 \%$ of the total production. Chickpea generally known as "Chana"/ "Gram" or "Bengal Gram" and widely appreciated as healthy food, is an essential legume having a broad variety of potential nutritional advantages due to its chemical composition (Aliu et al., 2016). In addition, it is important mainly for the developing countries, where people are mainly vegetarians and cannot afford the animal proteins for fulfilling their nutritional requirements. Despite India being the largest producer and

Aligarh Muslim University, Department of Botany, 202002 Aligarh, India.

* Corresponding author: aishasumbul92amu@gmail.com processor of chickpea in the world, the country also imports large amounts of this pulse annually in order to meet its ever-increasing consumption requirements.

Chickpea production in India has suffered in the last few years due to various constraints that include both biotic and abiotic stresses. Among these constraints, fungal and nematode attacks are considered as the major biotic factors causing significant yield losses in the crop. Meloidogyne incognita, one of the most damaging rootknot nematodes, causes significant losses on chickpea. Parasitism by $M$. incognita is characterised by the formation of root galls and deformation of the vascular system of the plant due to formation of giant cells and transfer of nutrients to these cells for use by the nematodes (Palomares-Rius, 2011; Sumbul et al., 2015). Macrophomina phaseolina, the causal agent of charcoal rot of chickpea, is an important pathogen causing considerable yield losses (Ashraf et al., 2005). The fungus is regularly reported from temperate 
and tropical areas of the world, including India, where it is most commonly associated with chickpea (Srivastava et al., 2001; Kumar et al., 2007; Naseri et al., 2018). Infection by $M$. phaseolina results in the formation of red to brown lesions on the roots and stems due to the presence of dark coloured mycelia and black microsclerotia. Eventually the plants become defoliated and wilted (Iqbal and Mukhtar, 2014). Interactive association between $M$. incognita and $M$. phaseolina results in a root-rot disease complex on chickpea that causes more serious yield losses as compared to their individual action (Siddiqui and Husain, 1991; 1992). A plethora of studies has been performed on interaction of nematode-fungus complex, yet there are limited reports on the interactive effects of $M$. incognita and $M$. phaseolina on chickpea.

The present study was performed to monitor the interactive effect of $M$. incognita and $M$. phaseolina on chickpea taking into account different times of inoculation with the two pathogens (individual, concomitant and sequential inoculation) and the associated alterations in growth, yield, physiology, nutrients, and pathogen-related parameters.

\section{Materials and Methods}

\section{Preparation and sterilization of soil mix- ture}

Sandy loam soil obtained from a field of the Aligarh Muslim University (AMU), India, was sieved using a 10-mesh sieve. The soil was subsequently mixed with river sand and organic manure in the ratio of 3:1:1. Clay pots (15 cm in diameter) were filled with the soil mixture $(1 \mathrm{~kg} / \mathrm{pot})$. Small amount of water was added to each pot to wet the soil prior to the steam sterilization of the pots at 1.36 atm pressure for 30 minutes. The pot study was conducted in a net house of the Department of Botany, AMU, Aligarh $\left(27^{\circ} .52^{\prime} \mathrm{N}\right.$ latitude, $78^{\circ} .51^{\prime} \mathrm{E}$ longitude) during the winter season (October to January).

\section{Growth and maintenance of test plants}

The chickpea seeds (var. Avrodhi) were surface sterilized by dipping in $0.01 \% \mathrm{HgCl}_{2}$ for $2 \mathrm{~min}$, followed by washing twice with distilled water. Prior to sowing, all seeds were treated with charcoal-based commercial culture of Rhizobium, chickpea strain. Five chickpea seeds were sown in each pot and the emerged seedlings were thinned to one seedling/pot. Watering of the pots was done as per requirement.

\section{Inoculum preparation of root-knot nem- atode Meloidogyne incognita}

Egg masses of $M$. incognita were handpicked using sterilized forceps from heavily infested roots of eggplant (Solanum melongena) on which pure culture of the nematode was maintained. The egg masses were rinsed with distilled water and placed in a coarse sieve (16 mesh size, $10 \mathrm{~cm}$ in diameter) covered with crossed double layers of tissue paper and placed in Petri plates containing water just deep enough to contact the egg masses. The Petri plates were incubated at $25^{\circ} \mathrm{C}$ in the dark. After three days, most of the eggs hatched and the second stage juveniles $\left(J_{2}\right)$ were collected by washing the Petri plates with distilled water.

The water containing hatched $J_{2}$ of $M$. incognita was thoroughly agitated for dispensing the nematodes homogenously in the suspension. The number of $J_{2}$ in the suspension was counted under the stereoscope. Five counts were made to calculate the average number of $J_{2} / \mathrm{mL}$ in the suspension of each sample and the final concentration was adjusted to $200 \pm 5 \mathrm{~J}_{2} / \mathrm{mL}$. Each plant was inoculated with $10 \mathrm{~mL}$ of the suspension containing 2000 freshly hatched $\mathrm{J}_{2}$.

\section{Mass culture of the root-rot fungus Mac- rophomina phaseolina}

Macrophomina phaseolina inoculum was obtained from the roots of naturally infected chickpea plants collected from fields in Aligarh district. The fungal culture was purified and maintained on Potato Dextrose Agar medium. Koch's postulates were applied to assure the pathogenicity of M. phaseolina on chickpea plants. Large amount of fungal inoculum (mycelium and spores) was 
obtained by mass culturing a M. phaseolina isolate in Richard's medium (Riker and Riker, 1936) for 15 days at $25^{\circ} \mathrm{C}$. The mycelium and spores were subsequently placed on blotting sheets to remove excess water and nutrients. The final inoculum consisting of a mixture of $100 \mathrm{gr}$ macerated wet mycelium and spores was added to $1 \mathrm{~L}$ of distilled water. Ten $\mathrm{mL}$ of the inoculum was used for the inoculation of each experimental plant.

\section{Inoculation techniques}

For the inoculation of plants with $M$. incognita and/or M. phaseolina the soil around the roots of one-week-old healthy chickpea seedlings was removed without causing any injury to the root system. Ten $\mathrm{mL}$ of inoculum suspension of $M$. incognita and/or M. phaseolina was poured around the roots, which were immediately covered with soil. An equal volume of distilled water was added to control plants.

\section{Experimental Design}

The experiment was carried out during the winter season in a completely randomized block design with the following variables:

(1) Uninoculated control

(2) M. incognita alone

(3) M. phaseolina alone

(4) M. incognita $+M$. phaseolina simultaneously

(5) M. incognita 15 days prior to M. phaseolina

(6) M. phaseolina 15 days prior to $M$. incognita

Five replicate pots were used for each treatment.

\section{Measurement of plant growth parame- ters}

The plants were harvested four months after emergence and washed gently under tap water to remove the adhering soil particles. Washed plants were labeled according to the treatments. Number of pods per plant and number of nodules per root system were counted visually. Plant height was measured with a measuring tape. Be- fore estimating the plant fresh weight with a physical balance, the excess of water was removed from the plants with blotting paper. For the determination of dry weight, the plants were air-dried in an oven at $60^{\circ} \mathrm{C}$ for 24 - $48 \mathrm{~h}$ before weighing.

\section{Leaf biochemical analysis}

Nitrate Reductase Activity (NRA) in leaves was measured by the process of Jaworski (1971). The nitrogen (N) content of the shoot was determined by the method of Lindner (1944), whereas phosphorus (P) and potassium (K) contents were determined by the method of Fiske and Subbarow (1925) and flame photometer, respectively. Chlorophyll and carotenoid contents of leaves were determined by the method of Hiscox and Israelstam (1979) using dimethyl sulphoxide (DMSO).

\section{Recording of gas exchange parameters of chickpea leaves}

Gas exchange parameters, such as photosynthesis rate $(\mathrm{Pn})$, transpiration rate $(\mathrm{E})$ and stomatal conductance (Sc), were measured in fully expanded uppermost leaves of plants with an Infra-Red Gas Analyser (IRGA, CID-340, Photosynthesis System, Bio Science, USA). The measurements were carried out on a sunny day at 11 a.m-12 p.m.

\section{Estimation of nematode reproduction in inoculated pots}

Number of galls per root system was counted visually. For estimating the number of egg-masses per root system, the method of Daykin and Hussey (1985) was followed. In order to determine the nematode population in soil, $1 \mathrm{~kg}$ of soil from each sample was processed by Cobb's sieving and decanting method, followed by Baermann funnel extraction technique (Southey, 1986). The reproductive potential of $M$. incognita in terms of reproduction factor (Rf) was calculated by dividing the final nematode population in soil by the nematode population used for inoculating the plants (Windham and Williams, 1987). 
Observations on percent root-rot in inoculated plants

To estimate the disease severity in terms of percent root-rot caused by M. phaseolina in chickpea, roots of each plant were initially cut into $5 \mathrm{~cm}$ pieces. The pieces were mixed together, and 15 pieces were randomly selected from the mixture. Each root piece was observed visually, and the length of the rotted portion was measured. The percentage of root-rot was estimated by using the following formula:

Root-rot $(\%)=\frac{\text { length of rotted portion on root pieces }}{\text { total length of root pieces }} \times 100$

Root rot index was determined according to four categories: $0=$ none; $1=$ less than $25 \% ; 2=26-50 \% ; 3=51-75 \% ; 4=76=100 \%$ (Aoyagi et al., 1998). Disease severity was calculated according to the following formula (Aoyagi et al., 1998):

Disease severity $(\%)=\Sigma \frac{\text { Disease index } x \text { No of plants in each category of index }}{\text { Higher value of the index } x \text { No of all inoculated plants }} \times 100$

\section{Statistical Analysis}

All the data were subjected to analysis of variance (ANOVA). Least significant differences (LSD) were calculated at $P \leq 0.05$ using $R$ software, version 2.14.0. Duncan's Multiple Range Test (DMRT) was deployed to denote significant differences between treatments.

\section{Results}

\section{Effect of interaction on growth and yield parameters of chickpea}

The highest growth parameters were observed in control plants. Both pathogens applied individually or in combination caused significant reduction in plant growth parameters, such as plant height and fresh as well as dry weights, compared to the control (Table 1). However, the highest reduction in plant growth was observed in plants inoculated simultaneously with the pathogens followed by those where nematode preceded the fungal inoculation by 15 days and those where the fungal preceded the nematode inoculation by 15 days. Mel- oidogyne incognita caused a higher reduction in plant growth as compared to that by M. phaseolina. Also, the statistical analysis of data showed that the reduction in all the growth parameters of plants inoculated simultaneously with the pathogens did not differ significantly from that of plants inoculated with $M$. incognita 15 days prior to M. phaseolina. Likewise, the highest reduction in the number of pods/plant was observed on plants treated with $M$. incognita + $M$. phaseolina and the lowest on plants inoculated with M. phaseolina alone (Table 1). A similar trend of reduction was observed in the number of nodules/root system.

\section{Effect of interaction on biochemicals and nutrients of chickpea leaves}

All the treatments, either individual or combined, caused significant reduction in the physiological and biochemical parameters of chickpea plants when compared to control plants. Biochemical and nutrients parameters, such as NRA, chlorophyll, carotenoids, N, P and $\mathrm{K}$ contents of the chickpea plants showed higher reductions in case of $M$. incognita $+M$. phaseolina inoculated plants compared to control plants. These reductions were not significant statistically when compared to those on plants inoculated with $M$. incognita 15 days prior to $M$. phaseolina inoculation (Table 2).

\section{Effect of interaction on gaseous ex- change rate of chickpea}

The highest photosynthetic rate $(\mathrm{Pn})$ was recorded in control plants while inoculation of plants with the pathogens, individually and in any combination, reduced photosynthetic rate significantly (Table 3 ). Maximum reduction in $\mathrm{Pn}$ was observed in plants treated with $M$. incognita $+M$. phaseolina followed by those where the nematode preceded the fungal inoculation by 15 days, those where the fungal preceded the nematode inoculation by 15 days, and those inoculated with $M$. incognita alone and $M$. phaseolina alone. Likewise, E and Sc exhibited the same trend of reduction as compared to control plants (Table 3). 
Table 1. Effects of Meloidogyne incognita and Macrophomina phaseolina, singly and combined, on growth, yield and nodulation of chickpea plants (Cicer arietinum var. avrodhi).

\begin{tabular}{|c|c|c|c|c|c|}
\hline \multirow{2}{*}{ Treatments } & \multirow{2}{*}{$\begin{array}{l}\text { Plant height } \\
\quad(\mathrm{cm})\end{array}$} & \multicolumn{2}{|c|}{ Plant weight (g) } & \multirow{2}{*}{$\begin{array}{l}\text { Number of } \\
\text { pods/plant }\end{array}$} & \multirow{2}{*}{$\begin{array}{c}\text { Number of } \\
\text { nodules/root } \\
\text { system }\end{array}$} \\
\hline & & Fresh & Dry & & \\
\hline Uninoculated control & $57.04^{*} \pm 2.29 a$ & $39.50 \pm 1.46 a$ & $7.12 \pm 0.31 a$ & $21.00 \pm 0.76 a$ & $43.00 \pm 0.71 a$ \\
\hline M. phaseolina alone & $48.40 \pm 1.62 b$ & $32.71 \pm 1.45 b$ & $5.68 \pm 0.32 b$ & $17.60 \pm 0.43 b$ & $36.60 \pm 0.71 b$ \\
\hline M. incognita alone & $44.94 \pm 1.30 \mathrm{~b}$ & $30.29 \pm 1.27 b$ & $5.24 \pm 0.27 b$ & $16.40 \pm 0.52 b c$ & $34.40 \pm 0.77 b c$ \\
\hline M. incognita + M. phaseolina & $30.68 \pm 0.99 d$ & $20.48 \pm 1.18 d$ & $3.49 \pm 0.26 d$ & $11.00 \pm 0.32 d$ & $23.20 \pm 0.71 d$ \\
\hline M. incognita $\rightarrow$ M. phaseolina & $34.40 \pm 1.16 d$ & $23.02 \pm 1.37 d$ & $3.94 \pm 0.24 d$ & $12.60 \pm 0.69 d$ & $26.20 \pm 0.63 d$ \\
\hline M. phaseolina $\rightarrow$ M. incognita & $39.56 \pm 0.89 c$ & $27.71 \pm 1.17 c$ & $4.78 \pm 0.31 c$ & $15.00 \pm 0.45 c$ & $31.40 \pm 0.45 c$ \\
\hline
\end{tabular}

$+=$ simultaneous inoculation with both pathogens, $\rightarrow=$ nematode or fungal inoculation preceded by 15 days the fungal or the nematode inoculation, respectively. *Values are means of five replicates. Means in each column followed by the same letter(s) do not differ significantly at $P \leq 0.05$.

Table 2. Effects of Meloidogyne incognita and Macrophomina phaseolina, singly and combined, on nitrate reductase activity (NRA), nitrogen (N), phosphorus (P) and potassium (K) contents of chickpea plants (Cicer arietinum var. avrodhi).

\begin{tabular}{|c|c|c|c|c|}
\hline \multirow{2}{*}{ Treatments } & \multirow{2}{*}{$\begin{array}{c}\text { NRA } \\
(\mu \mathrm{mol} N O 2 / \mathrm{g} / \mathrm{h})\end{array}$} & \multicolumn{3}{|c|}{ Fresh leaf content (mg/g) } \\
\hline & & $\mathrm{N}$ & $\mathrm{P}$ & $\mathrm{K}$ \\
\hline Uninoculated control & $0.397^{*} \pm 0.006 a$ & $3.220 \pm 0.065 a$ & $0.310 \pm 0.006 a$ & $1.570 \pm 0.036 a$ \\
\hline M. phaseolina alone & $0.353 \pm 0.008 b$ & $2.896 \pm 0.055 b$ & $0.282 \pm 0.006 b$ & $1.458 \pm 0.031 b$ \\
\hline M. incognita alone & $0.330 \pm 0.008 b c$ & $2.727 \pm 0.058 b c$ & $0.266 \pm 0.007 b c$ & $1.364 \pm 0.029 b c$ \\
\hline M. incognita + M. phaseolina & $0.280 \pm 0.006 d$ & $2.297 \pm 0.048 d$ & $0.229 \pm 0.006 \mathrm{e}$ & $1.189 \pm 0.029 \mathrm{e}$ \\
\hline M. incognita $\rightarrow$ M. phaseolina & $0.296 \pm 0.006 d$ & $2.428 \pm 0.030 d$ & $0.241 \pm 0.006 \mathrm{de}$ & $1.228 \pm 0.028 \mathrm{de}$ \\
\hline M. phaseolina $\rightarrow$ M. incognita & $0.322 \pm 0.008 c$ & $2.645 \pm 0.055 c$ & $0.259 \pm 0.007 c d$ & $1.317 \pm 0.030 \mathrm{~cd}$ \\
\hline
\end{tabular}

$+=$ simultaneous inoculation with both pathogens, $\rightarrow=$ nematode or fungal inoculation preceded by 15 days the fungal or the nematode inoculation, respectively. ${ }^{*}$ Values are means of five replicates. Means in each column followed by the same letter(s) do not differ significantly at $\mathrm{P} \leq 0.05$.

Table 3. Effects of Meloidogyne incognita and Macrophomina phaseolina, singly and combined, on chlorophyll, carotenoid, photosynthesis rate $(\mathrm{Pn})$, transpiration rate (E) and stomatal conductance (Sc) of chickpea plants (Cicer arietinum var. avrodhi).

\begin{tabular}{|c|c|c|c|c|c|}
\hline \multirow{2}{*}{ Treatments } & \multicolumn{2}{|c|}{ Fresh leaf content (mg/g) } & \multirow{2}{*}{$\begin{array}{c}\mathrm{Pn} \\
(\mu \mathrm{mol} / \\
\mathrm{m} 2 / \mathrm{sec})\end{array}$} & \multirow{2}{*}{$\begin{array}{c}\mathrm{E} \\
\text { (nmol/ } \\
\mathrm{m} 2 / \mathrm{sec} \text { ) }\end{array}$} & \multirow{2}{*}{$\begin{array}{c}\mathrm{Sc} \\
\text { (nmolH2O/ } \\
\mathrm{m} 2 / \mathrm{sec})\end{array}$} \\
\hline & Chlorophyll & & & & \\
\hline Uninoculated control & $140 * \pm 0.036 a$ & $0.142 \pm 0.001 a$ & $9.284 \pm 0.009 a$ & $1.711 \pm 0.006 a$ & $280.236 \pm 0.018 a$ \\
\hline M. phaseolina alone & $1.876 \pm 0.035 b$ & $0.126 \pm 0.002 b$ & $7.441 \pm 0.011 b$ & $1.483 \pm 0.005 b$ & $244.114 \pm 0.016 b$ \\
\hline M. incognita alone & $1.756 \pm 0.017 b c$ & $0.119 \pm 0.001 b c$ & $7.127 \pm 0.008 b c$ & $1.376 \pm 0.005 b c$ & $233.773 \pm 0.025 b c$ \\
\hline M. incognita + M. phaseolina & $1.458 \pm 0.023 d$ & $0.099 \pm 0.001 d$ & $5.083 \pm 0.008 d$ & $1.057 \pm 0.003 d$ & $191.457 \pm 0.025 \mathrm{e}$ \\
\hline M. incognita $\rightarrow$ M. phaseolina & $1.548 \pm 0.022 \mathrm{~cd}$ & $0.105 \pm 0.001 d$ & $5.343 \pm 0.007 d$ & $1.152 \pm 0.006 d$ & $202.190 \pm 0.021 \mathrm{de}$ \\
\hline M. phaseolina $\rightarrow$ M. incognita & $1.675 \pm 0.023 c$ & $0.115 \pm 0.002 c$ & $6.655 \pm 0.007 c$ & $1.331 \pm 0.003 c$ & $220.686 \pm 0.019 \mathrm{~cd}$ \\
\hline
\end{tabular}

$+=$ simultaneous inoculation of both pathogens, $\rightarrow=$ nematode or fungal inoculation preceded by 15 days the fungal or the nematode inoculation, respectively. *Values are means of five replicates. Means in each column followed by same letter(s) do not differ significantly at $P \leq 0.05$. 
Effect of interaction on nematode and fungal multiplication related parameters on chickpea

The greatest Rf, number of galls and eggmasses/root system were recorded in plants inoculated with $M$. incognita alone (Table 4). The multiplication of $M$. incognita and the number of galls/root system in chickpea plants were significantly hampered in the presence of $M$. phaseolina as compared to plants inoculated with $M$. incognita alone. The greatest reduction was observed in plants inoculated with M. phaseolina 15 days prior to $M$. incognita inoculation, followed by those inoculated simultaneously with $M$. incognita and $M$. phaseolina and those where $M$. incognita preceded M. phaseolina inoculation by 15 days. Similar trend of reduction was recorded in case of the final population of $M$. incognita recovered from the soil of the treated pots. On the other hand, the highest disease severity was observed in $M$. incognita + M. phaseolina inoculated plants followed by plants inoculated with the nematode 15 days prior to fungal inoculation, by plants where the fungal preceded the nematode inoculation by 15 days, and by plants inoculated only with M. phaseolina. Similarly, the highest root-rot index was recorded in $M$. incognita $+M$. phaseolina inoculated plants, followed by those inoculated with $M$. incognita 15 days prior to M. phaseolina, by plants where the fungal inoculation preced- ed the nematode inoculation by 15 days and by plants inoculated only with $M$. phaseolina (Table 4).

\section{Discussion}

It is evident from the present study that the highest and most significant decrease in growth and yield parameters was observed in chickpea plants inoculated simultaneously with $M$. incognita and $M$. phaseolina, which shows a synergistic effect between the fungus and the nematode (Singh et al. 2010; Ganaie and Khan, 2011; Ahmed et al., 2014). Simultaneous inoculation of plants with the pathogens significantly damaged the roots and root hairs leading to low capacity of the plants to absorb water and nutrients from the soil. The lack of water and nutrients in the plants resulted in poor growth in terms of reduced plant height, fresh and dry weights (Ansari and Mahmood, 2017). The reduction in growth and yield observed in plants inoculated with M. phaseolina 15 days prior to $M$. incognita was equal to that in nematode inoculated plants although the fungus had enough time to colonize the roots and make them less suitable for the penetration by the nematode (Meena et al., 2016). It is also possible that the toxic metabolites produced by M. phaseolina may have destroyed the giant cells which are necessary for the nematode

Table 4. Effects of Meloidogyne incognita and Macrophomina phaseolina, singly and combined, on disease development in chickpea plants (Cicer arietinum var. avrodhi).

\begin{tabular}{l|c|c|c|c|c|c}
\hline Treatments & $\begin{array}{c}\text { Number of } \\
\text { galls/root } \\
\text { system }\end{array}$ & $\begin{array}{c}\text { Number of } \\
\text { egg-masses/ } \\
\text { root system }\end{array}$ & $\begin{array}{c}\text { Number of } \\
\text { nematode } \\
\text { juveniles/kg soil }\end{array}$ & $\begin{array}{c}\text { Repro- } \\
\text { duction } \\
\text { factor } \\
\text { (Rf) }\end{array}$ & $\begin{array}{c}\text { Disease } \\
\text { severity (per- } \\
\text { cent root-rot) }\end{array}$ & $\begin{array}{c}\text { Root-rot } \\
\text { disease } \\
\text { index } \\
(0-4)\end{array}$ \\
\hline Uninoculated control & $0.00^{*} \pm 0.00 \mathrm{e}$ & $0.00 \pm 0.00 \mathrm{e}$ & $0.00 \pm 0.00 \mathrm{e}$ & 0.00 & $0.00 \pm 0.00 \mathrm{e}$ & 0 \\
M. phaseolina alone & $0.00 \pm 0.00 \mathrm{e}$ & $0.00 \pm 0.00 \mathrm{e}$ & $0.00 \pm 0.00 \mathrm{e}$ & 0.00 & $21.23 \pm 1.45 \mathrm{~d}$ & 1 \\
M. incognita alone & $114.40 \pm 4.17 \mathrm{a}$ & $107.20 \pm 2.17 \mathrm{a}$ & $19659 \pm 321.89 \mathrm{a}$ & 9.82 & $0.00 \pm 0.00 \mathrm{e}$ & 0 \\
M. incognita + M. phaseolina & $79.20 \pm 3.40 \mathrm{c}$ & $61.00 \pm 0.98 \mathrm{c}$ & $12771 \pm 155.05 \mathrm{c}$ & 6.38 & $64.21 \pm 2.55 \mathrm{a}$ & 3 \\
M. incognita $\rightarrow$ M. phaseolina & $93.20 \pm 4.73 \mathrm{~b}$ & $83.60 \pm 1.50 \mathrm{~b}$ & $14416 \pm 222.99 \mathrm{~b}$ & 7.20 & $59.14 \pm 2.70 \mathrm{~b}$ & 3 \\
M. phaseolina $\rightarrow$ M. incognita & $69.40 \pm 2.84 \mathrm{~d}$ & $53.00 \pm 2.97 \mathrm{~d}$ & $11605 \pm 248.16 \mathrm{~d}$ & 5.80 & $46.41 \pm 1.73 \mathrm{c}$ & 2 \\
\hline
\end{tabular}

$+=$ simultaneous inoculation of both pathogens, $\rightarrow=$ nematode or fungal inoculation preceded by 15 days the fungal or the nematode inoculation, respectively. *Values are means of five replicates. Means in each column followed by same letter(s) do not differ significantly at $P \leq 0.05$. 
feeding and reproduction (Ogaraku, 2008; Ahmed et al., 2014).

The significant damage to the root nodules observed in plants inoculated with the pathogens, either individually or simultaneously may be due to the heavy galling resulting from $M$. incognita infection, destruction of root tissue by the rotting caused by $M$. phaseolina and/or the inhibitory effects of $M$. incognita and $M$. phaseolina generated toxic metabolites on Rhizobium (Hussain and Siddiqui, 1991; 1992). Plants with lower number of nodules were able to fix lesser nitrogen into nitrate, depriving the plants with suitable substrate for the nitrate reductase enzyme. The decrease in NRA in inoculated plants indicates adverse effect of $M$. incognita and $M$. phaseolina on protein synthesis (Naik et al., 1982). This decrease also resulted in reduced growth and yield of chickpea plants. Chlorophyll and nutrient (N, P and K) contents of plants also decreased with the highest reduction observed in plants inoculated simultaneously with the pathogens. Plants inoculated simultaneously with both pathogens showed extremely damaged roots with hampered translocation of water and nutrients from roots to the upper parts (Ansari and Mahmood, 2017). Also, the rootknot nematode directs nutrient contents towards the infected giant cells for their own feeding and reproduction, thus depriving the upper parts of the plants from proper nutrient content levels (Sumbul and Mahmood, 2017).

Gaseous exchange parameters, Pn, E and $\mathrm{Sc}$, were highly reduced in $M$. incognita + M. phaseolina inoculated plants which may be due to severe infection of the roots resulting in hampered water absorption and nutrient translocation acropetally (Lorenzini et al., 1997; Saeed et al., 1999; Strajnar, 2012). Ghazalbash and Abdollahi (2012) reported a decrease in gaseous exchange parameters in tomato plants infected simultaneously with Meloidogyne javanica and Fusarium oxysporum f. sp. lycopersici. The authors assumed that stomatal closure reduces the intercellular $\mathrm{CO}_{2}$ concentration, which might be the cause behind the reduced net pho- tosynthesis.

The reduced number of galls and eggmasses per root system in the presence of $M$. phaseolina indicates that this fungus is deleterious for the multiplication of $M$. incognita. The detrimental effect of $M$. phaseolina on $M$. incognita multiplication may be due to the destruction of root tissues which become unable to support a large number of galls thus affecting $M$. incognita reproduction (Back et al., 2002; Al-Hazmi and AlNadri, 2015; Meena et al., 2016). Decrease in feeding sites impaired nutrient supply to nematode (Hasan 1993; Fazal et al., 1998). Moreover, the toxic substances produced by the fungus resulted in the destruction of the giant cells induced by the nematode, as well as in reduction in hatching and immobilization of $\mathrm{J}_{2}$ (France and Abawi, 1994; Mokbel et al., 2007). Plants inoculated with $M$. incognita 15 days prior to M. phaseolina produced higher number of egg-masses, galls and nematode population as compared to those inoculated simultaneously with both pathogens (Ogaraku, 2008).

The lowest disease severity was recorded in plants inoculated with M. phaseolina alone. Our results are in conformity with those of Senthamarai (2006), Ganaie and Khan (2011) and Ahmed et al. (2014). The low disease severity indicates that $M$. phaseolina could not infect the host in the absence of the predisposing factor, i.e. M. incognita in this case (Siddiqui and Hussain, 1991; Lobna et al., 2016). The highest rotting of chickpea roots was observed when plants were inoculated simultaneously with $M$. incognita and M. phaseolina. This may be because both pathogens had equal opportunities to infect the plants, but the presence of the nematode further enhanced the susceptibility of roots to fungal infection (Ganaie and Khan, 2011; Ahmed et al., 2014).

The root-rot fungus has an inherent mechanism to get entry into the root and cause root-rot disease. However, in the case of root-rot disease complex, nematode plays a crucial role in assisting the fungus in its pathogenesis and enhancing host susceptibility (Khan, 1984). Wounds caused by 
the nematode on plant roots provide entry points for the fungus to infect the roots more rigorously (Inagaki and Powell, 1969). Apart from the wounds, nematodes also lead to different forms of damage to plant roots like split root galls, cracks and crevices due to emergence of swollen females etc. thus allowing the fungus to infect the host root (Evan and Haylock, 1993, Back et al., 2002). In addition to morphological disruptions, alterations in the physiological and nutrient status of the root cells infected by the nematode may also be responsible for the appearance of the root-rot disease complex. Giant cells produced by the root-knot nematode are the regions of high metabolic activity (Jones, 1981). These physiological alterations lead to better nutrients availability to the invading fungus and serve as the key factor in establishing the nematode-fungus disease complex (Khan and Muller, 1982; Khan, 1987; Abdel-Momen and Starr, 1998; Castillo et al., 1998). Plant root exudates play a key role in attracting both nematode and fungal pathogens (Grayston, 1997; Clarke and Henessy, 1987). Therefore, the rootknot nematode might have altered the root exudates either quantitatively or qualitatively, making them more favourable for the growth of the fungus (Bergeson, 1972; Golden and Van Gundy, 1975; Reddy 1980).

\section{Conclusions}

It can be inferred from the present study that the presence of $M$. incognita increased the severity of the root-rot disease caused by M. phaseolina in chickpea plants. The interaction between $M$. incognita and $M$. phaseolina even modified the biochemical composition in the plants to assist the growth and multiplication of the pathogens. Therefore, inoculation of plants with both pathogens (either simultaneous or sequential) caused higher damage compared to individual inoculations. However, the greatest damage was observed in plants inoculated simultaneously with the pathogens. When present together, the pathogens caused significant reduction in chickpea growth and yield and modified physiological and biochemical components of the plants to support their growth accordingly. Moreover, $M$. incognita proved to act as a predisposing factor for the infection of plants by M. phaseolina. Thus, the interaction between $M$. incognita and $M$. phaseolina should be taken into consideration for the development of strategies for the effective management of the rootrot disease complex in chickpea crops.

Both authors declare that they do not have any conflict of interest.

\section{Literature Cited}

Abawi, G.S. and Barker, K.R. 1984. Effects of cultivar, soil temperature, and population levels of Meloidogyne incognita on root-necrosis and Fusarium wilt of tomatoes. Phytopathology, 74: 433438.

Abdel-Momen, S.M. and Starr, J.L. 1998. Meloidogyne javanica-Rhizoctonia solani disease complex of peanut. Fundamental and Applied Nematology, 21: 611-6.

Ahmed, D., Shahab, S. and Safiuddin. 2014. Disease complex of Meloidogyne incognita and Fusarium solani on Chilli (Capsicum annuum L.). Journal of Natural Product and Plant Resources, 4 (5): 14-18.

Al-Hazmi, A.S. and Al-Nadary, S.N. 2015. Interaction between Meloidogyne incognita and Rhizoctonia solani on green beans. Saudi Journal of Biological Sciences, 22: 570-574.

Ali, L., Deokar, A., Caballo, C., Tar'an, B., Gil, J., Chen, W., Millan, T. and Rubio, J. 2016. Fine mapping for double podding gene in chickpea. Theoretical and Applied Genetics, 129(1): 77-86.

Aliu, S., Kaul, H.P., Rusinovci, I., Shala-May, V., Fetahu, S. and Zeka, D. 2016. Genetic diversity for some nutritive traits of chickpea (Cicer arietinum L.) From different regions in Kosova. Turkish Journal of Field Crops, 21(1): 155-160.

Ansari, R.A. and Mahmood, I. 2017. Optimization of organic and bio-organic fertilizers on soil properties and growth of pigeon pea. Scientia Horticulturae, 226: 1-9.

Aoyagi, T., Kageyama, K. and Hyakumachi, M. 1998. Characterization and survival of Rhizoctonia solani AG2-2 LP associated with large patch disease of Zoysia grass. Plant Disease, 82: 857-863.

Ashraf, M.S. and Khan, T.A. 2005. Effect of opportunistic fungi on the life cycle of the rootknot nematode (Meloidogyne javanica) on brinjal. Ar- 
chives of Phytopathology and Plant Protection, 38 (3): 227-233 ISSN 0323-5408.

Back, M.A., Haydock, P.P.J. and Jenkinson P. 2002. Disease complexes involving plant parasitic nematodes and soilborne pathogens, Plant $\mathrm{Pa}$ thology, 51: 683-697.

Bergeson, G.B. 1972. Concepts of nematode-fungus associations in plant disease complexes: a review. Experimental Parasitology, 32: 301-14.

Castillo, P., Mora-Rodriguez, M.P., Navas-Cortés, J.A. and Jiménez-Díaz, R.M. 1998. Interactions of Pratylenchus thornei and Fusarium oxysporum f. sp. ciceris on chickpea. Phytopathology, 88(8): $828-836$.

Chahal, P.P.K. and Chahal, V.P.S. 1991. Effect of Rhizobium and root-knot nematodes in nitrogen fixation and nitrate utilization in chickpea (Cicer arietinum L.). Journal of Ravishankar University, 4-5(B): 43-45.

Clarke, A.J. and Hennessy, J. 1987. Hatching agents as stimulants of movement of Globodera rostochiensis juveniles. Revue de Nematologie, 10: 471-6.

Daykin, M.E. and Hussey, R.S. 1985. Staining and histopathological techniques in nematology. In: Barker, K.R., Carter, C.C., Sasser, J.N. (eds.): An advance treatise on Meloidogyne. - Vol. II: Methodology, PP. 39-48. North Carolina State University Graphics, 1.

Evans, K. and Haydock, P.P.J. 1993. Interactions of nematodes with root-rot fungi. In: Wajid Khan M, ed. Nematode Interactions. London, UK: Chapman \& Hall, 104-33.

Fazal, M., Khan, M.I., Raza, M.M.A. and Siddiqui, Z.A. 1994. Interaction between Meloidogyne incognita and F. oxysporum f. sp. lentis on lentil. Nematologia Mediterranea, 2: 185-187.

Fiske, C.H. and Subbarow, Y. 1925. The colorimetric determination of phosphorus. Journal of Biological Chemistry, 66: 375-400.

Food and Agriculture Organization of the United Nations statistical database (FAOSTAT), (2016). FAO Statistical Databases. Online database, http://faostat.fao.org/.

Food and Agriculture Organization of the United Nations statistical database (FAOSTAT), (2015). FAO Statistical Databases. Online database, http://faostat.fao.org/.

France, R.A. and Abawi, G.S. 1994. Interaction between Meloidogyne incognita and Fusarium oxysporum f.sp. phaseoli on selected bean genotypes. Journal of Nematology, 26: 467-474.

Ganaie, M.A. and Khan, T.A. 2011. Studies on the interactive effect of Meloidogyne incognita and Fusarium solani on Lycopersicon esculentum, Mill. International Journal of Botany, 7(2): 205-208.

Ghazalbash, N. and Abdollahi, M. 2012. Effect of medicinal plant extracts on physiological changes in tomato, inoculated with Meloidogyne javanica and Fusarium oxysporum f. sp. lycopersici, Pakistan Journal of Nematology, 31 (1): 21-37.

Golden, J.K. and Van Gundy, S.D. 1975. A disease complex of okra and tomato involving the nematode Meloidogyne incognita, and the soil-inhabiting fungus, Rhizoctonia solani. Phytopathology, 65: 265-73.

Grayston, S.J., Vaughan, D. and Jones, D. 1997. Rhizosphere carbon flow in trees, in comparison with annual plants: the importance of root exudation and its impact on microbial activity and nutrient availability. Applied Soil Ecology, 5: 29-56.

Hasan, A. 1989. Efficacy of certain non-fumigant nematicides on the control of pigeon pea wilt involving Heterodera cajani and Fusarium udum. Phytopathology, 126: 335-342.

Hiscox, J.D. and Israelstam, G.F. 1979. A method for the extraction of chlorophyll from leaf tissue without maceration. Canadian Journal of Botany, 57: 1332-1334.

Hussey, R.S. and Barker, K.R.A. 1973. Comparison of methods of collecting inocula of Meloidogyne spp., including a new technique. Plant Disease, 57: 1025-1028.

Inagaki, H. and Powell, N.T. 1969. Influence of the root-lesion nematode on black shank symptom development in flue-cured tobacco. Phytopathology, 59: 1350-5.

Iqbal, U. and Mukhtar, T. 2014. Morphological and Pathogenic Variability among Macrophomina phaseolina Isolates Associated with Mungbean (Vigna radiata L.) Wilczek from Pakistan. Scientific World Journal Article ID 950175, 9 pages.

Jaworski, E.G. 1971. Nitrate reductase assay in intact plant tissues. Biochemical and Biophysical Research Communications, 43: 1274-1279.

Jones, M.G.K. 1981. Host cell responses to endoparasitic attack: structure and function of giant cells and syncytia. Annals of Applied Biology, 97: 353-72.

Khan, M.W. and Muller, J. 1982. Interaction between Rhizoctonia solani and Meloidogyne hapla in gnotobiotic culture. Libyan Journal of Agriculture, 11: 133-40.

Kumar, V., Kumar, A. and Kharwar, R.N. 2007. Antagonistic potential of fluorescent Pseudomonads and control of charcoal rot of Chickpea caused by Macrophomina phaseolina. Journal of Environmental Biology, 28(1): 15-20.

Lindner, R.C. 1944. Rapid analytical methods for some of the more common inorganic constituents of plant tissue. Plant Physiology, 19: 76-89.

Lindner, S. 1974. A proposal for the use of standardized methods for chlorophyll determinations in ecological and eco-physiological investigations. Physiologia Plantarum, 32: 154-156.

Lobna, H., Hajer, R., Naima, M. and Najet, H. 2016. 
Studies on Disease Complex Incidence of Meloidogyne javanica and Fusarium oxysporum f. sp. lycopersici on resistant and susceptible tomato cultivars. Journal of Agricultural Science and Food Technology, 2 (4): 41-48.

Lorenzini, G., Guidi, L., Nali, C., Ciompi, S. and Sodatin, G.F. 1997. Photosynthetic response of tomato plants to vascular wilt diseases. Plant Science, 124: $143-52$.

Meena, K.S., Ramyabharathi, S.A., Raguchander, T. and Jonathan, E.I. 2016. Interaction of Meloidogyne incognita and Fusarium oxysporum in carnation and physiological changes induced in plants due to the interaction. SAARC Journal of Agriculture, 14(1): 59-69.

Mohiddin, F.A. Khan, and M.R. 2014. Root-knot nematode: Ignored soil borne plant pathogen causing root diseases of chickpea. European Journal of Biotechnology and Bioscience, 2 (1): 04-10

Mokbel, A.A., Ibrahim, I.K.A., Shehata, M.R.A. and El-Saedy, M.A.M. 2007. Interaction between certain root rot disease fungi and root-knot nematode Meloidogyne incognita on sunflower plants. Egyptian Journal of Phytopathology, 35: 1-11.

Naik, M.S., Abrol, Y.P., Nair, T.V.R. and Ramarao, C.S. 1982. Nitrate assimilation-its regulation and relationship to reduced nitrogen in higher plants. Phytochemistry, 21: 495-504.

Naseri, B., Veisi, M. and Khaledi, N. 2018. Towards a better understanding of agronomic and soil basis for possible charcoal root rot control and production improvement in bean. Archives of Phytopathology and Plant Protection, 1-10.

Ogaraku, A.O. 2008. Separate and combined effect of Fusarium oxysporum f. sp. tracheiphilum and Meloidogyne incognita on growth and yield of cowpea (Vigna unguiculata L. Walp) var. Moussa-local. Plant Pathology Journal, 7(1): 114-117.

Oostenbrink, M. 1966. Major Characteristics of the Relation Between Nematodes and Plants. Landbooughwhogesch. Wageningen 66-4. 46 pp.

Palomares-Rius, J.E., Castillo, P., Juan, A., Navas-Cortés, Jiménez-Díaz, R.M. and Tena, M. 2011. A proteomic study of in-root interactions between chickpea pathogens: The root-knot nematode Meloidogyne artiellia and the soil-borne fungus Fusarium oxysporum f. sp. ciceris race 5. Journal of Proteomics, 74: 2034 - 2051.

Reddy, M.N. 1980. Studies on groundnut hypocotyl exudates and the behaviour of Rhizoctonia solani in influencing disease. Plant and Soil, 55: 445-54.

Riker, R.J. and Riker, R.S. 1936. Introduction to Research on Plant Disease. John's Swift Co. Inc. St. Louis Chicago, New York Indianapolis, 117.
Rizvi, R., Mahmood, I. and Ansari, S. 2016. Interaction between plant symbionts, bio-organic waste and antagonistic fungi in the management of Meloidogyne incognita infecting chickpea. Journal of Saudi Society of Agricultural Sciences, (In Press).

Saeed, I.A.M., McGuidwin, A.E., Rouse, D.I. and Sharkey, T.D. 1999. Limitation to photosynthesis in Pratylenchus penetrans and Verticillium dahliaeinfected potato. Crop Science, 39: 1340-1346.

Senthamarai, M., Poornima, K., Subramanian, S. and Sudheer, M.J. 2008. Nematode-fungal disease complex involving Meloidogyne incognita and Macrophomina phaseolina on medicinal coleus, Coleus forskohlii Briq. Indian Journal of Nematology, 38(1): 30-33.

Siddiqui, Z.A. and Husain, S.I. 1991. Interaction of Meloidogyne incognita race-3 and Macrophomina phaseolina in root-rot disease complex of chickpea. Nematologia Mediterranea, 19: 237239.

Siddiqui, Z.A. and Husain, S.I. 1992. Biocontrol of a chickpea root-rot disease complex with Glomus intraradices, Pseudomonas putida and Paenibacillus polymyxa. Fundamental and Applied Nematology, 16: 491-494.

Southey, J.F. 1986. Laboratory methods for work with plant and soil nematodes. In: Ministry of Agriculture, Fish. Food. HMSO, London.

Srivastava, A.K., Singh, T., Jana, T.K. and Arora, D.K. 2001. Microbial colonization of Macrophomina phaseolina and suppression of charcoal rot of chickpea A. Sinha (Ed.), Microbes and plants, Vedams eBooks (P) Ltd, New Delhi, pp. 269-319.

Strajnar, P., irca, S., Urek, G., ircelj, H., Železnik, P. and Vodnik, D. 2012. Effect of Meloidogyne ethiopica parasitism on water management and physiological stress in tomato, Eurasian Journal of Plant Pathology, 132:49-57.

Sumbul, A., Rizvi, R., Mahmood, I. and Ansari, R.A. 2015. Oil-Cake Amendments: Useful Tools for the Management of Phytonematodes. Asian Journal of Plant Pathology, 9: 91-111.

Windham, G.L. and Williams, W.P. 1987. Host suitability of commercial corn hybrids to Meloidogyne arenaria and Meloidogyne incognita. Journal of Nematology, 19 (Annals 1): 13-16.

Received: 3 August 2018; Accepted: 23 July 2019 


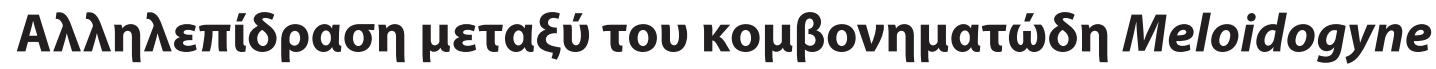

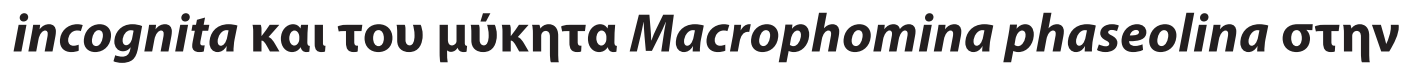

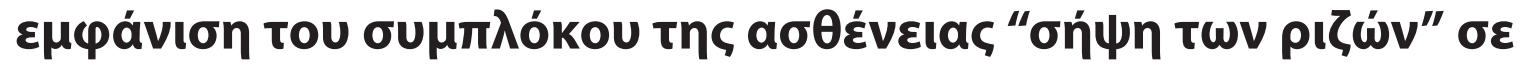

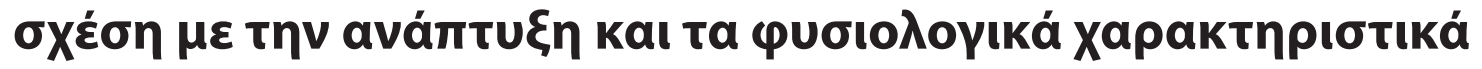

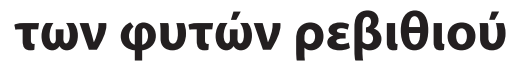

\section{A. Sumbul kaı I. Mahmood}

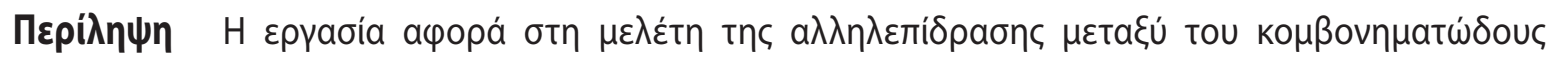

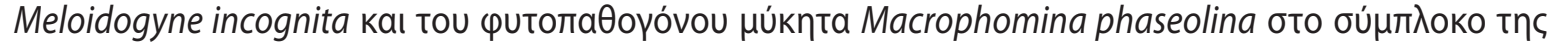

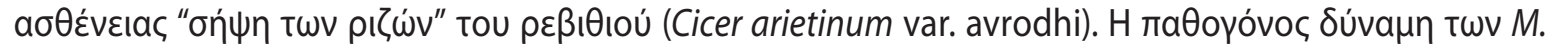

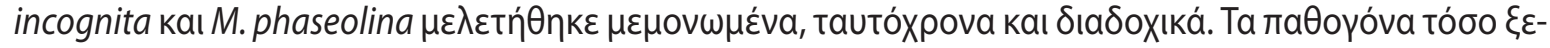

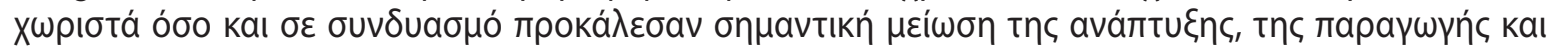

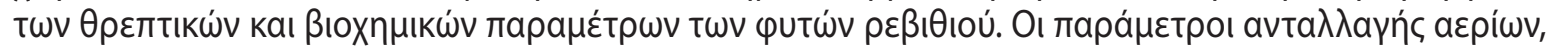

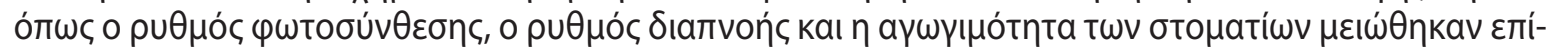

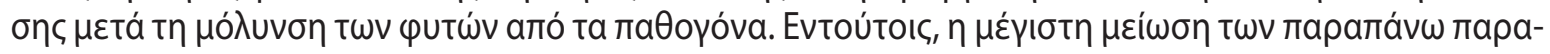

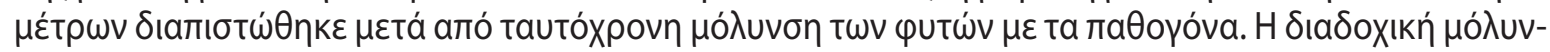

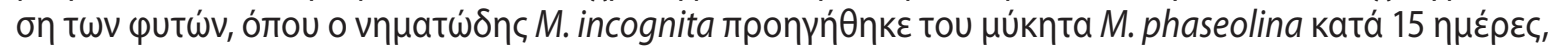

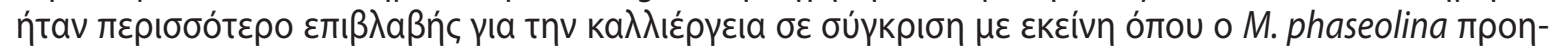

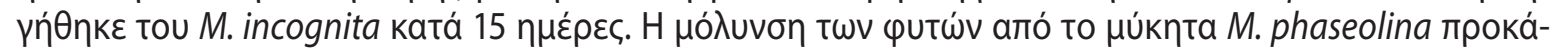

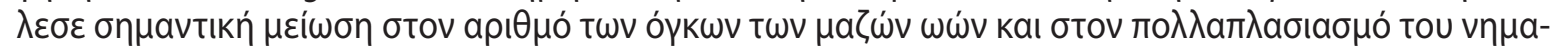

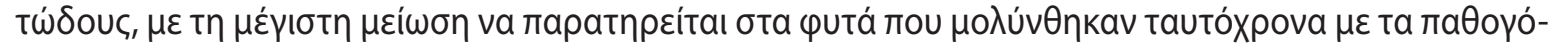

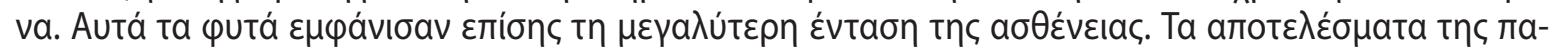

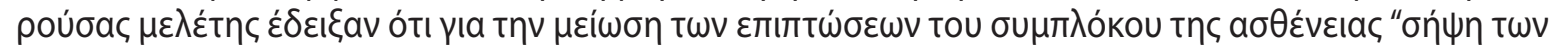

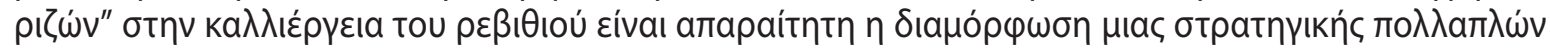

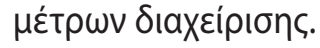

